\title{
EpiReview: Tuberculosis in NSW, 2008
}

\author{
April R. Roberts-Witteveen ${ }^{\mathrm{A}, \mathrm{B}}$, Amanda \\ J. Christensen ${ }^{\mathrm{A}}$ and Jeremy M. Mc Anulty $^{\mathrm{A}}$ \\ ${ }^{\mathrm{A}}$ Communicable Diseases Branch, NSW Department of Health \\ ${ }^{\mathrm{B} C o r r e s p o n d i n g ~ a u t h o r . E m a i l: ~ a r o b e @ d o h . h e a l t h . n s w . g o v . a u ~}$
}

\begin{abstract}
Aim: To describe the epidemiology of tuberculosis cases notified in NSW in 2008. Method: Data on tuberculosis cases resident in NSW that were reported in 2008 were extracted from the Notifiable Diseases Database. Demographic, microbiological, clinical and other characteristics of cases were described. Incidence rates per 100000 were calculated. Results: In 2008, 498 tuberculosis cases were notified in NSW (7.1 cases per 100000 population). Most cases were newly diagnosed ( $n=479,96 \%)$. The lung was the most common site of disease $(n=304,61 \%)$. Eight of 269 tested cases (1.6\%) had a HIV-tuberculosis co-infection. One case had multidrug-resistant tuberculosis. Most cases reported past residence ( $n=429,86 \%)$ or birth ( $n=378,76 \%)$ in a country with a high incidence of tuberculosis. Conclusion: The incidence of tuberculosis in NSW increased slightly in 2008. Most cases had links to countries with a high tuberculosis incidence.
\end{abstract}

Tuberculosis (TB) is caused by infection with Mycobacterium tuberculosis. ${ }^{1}$ Globally in 2008, there were an estimated 9.6 to 13.3 million prevalent cases of TB. ${ }^{2}$ Of the estimated 5.7 million new TB infections in 2008, approximately 55\% lived in Asia. ${ }^{2}$ In Australia, TB control continues to be a challenge, despite relatively low incidence rates when compared to many countries. ${ }^{3}$ In New South Wales (NSW), the incidence of TB was between 5.6 and 6.8 cases per 100000 population between 2003 and $2007 .^{4}$

Most people with M. tuberculosis infection harbour the bacterium without symptoms (latent infection). When people acquire a TB infection, they have about a $10 \%$ chance of developing active disease in their lifetime; approximately half of those who develop TB do so within 2 years of infection. ${ }^{5}$ People with active pulmonary TB may be infectious to others and transmission can occur when TB bacilli are expelled into the air by coughing, sneezing or talking. Two to four weeks of treatment with appropriate multidrug therapy, usually including the antibiotics isoniazid, rifampicin, pyrazinamide and ethambutol renders most people non-infectious. ${ }^{5}$

Multidrug-resistant tuberculosis (MDR-TB) occurs when the organism causing disease is resistant to at least isoniazid and rifampicin. ${ }^{6}$ Globally, the proportion of all TB cases that are MDR-TB increased from $1.7 \%$ between 1997 and $2002^{6}$ to $5.3 \%$ in the period $2002-2007 .{ }^{7}$ Of an estimated 500000 cases worldwide in 2007, approximately $258000(52 \%)$ lived in India, China and Bangladesh. ${ }^{2}$ In Australia in 2007, 2.8\% of TB cases were MDR-TB. ${ }^{8}$

In NSW, TB is a notifiable disease under the NSW Public Health Act 1991 and laboratories, doctors and hospitals must report all cases to their local public health unit. Staff in public health units or chest clinics enter case details into the Notifiable Diseases Database (NDD), a confidential database maintained by the Communicable Diseases Branch of the NSW Department of Health.

This report reviews the demographic, microbiological, clinical and other characteristics of patients notified with TB in NSW in 2008.

\section{Methods}

In this report the term 'TB cases' is used to refer to people who have been notified with active TB disease. All TB cases are assigned the reporting year based on the year in which the diagnostic, clinical and public health actions occurred. Information about cases with a reporting year of 2008 was extracted from the NDD for analysis.

Incidence rates per 100000 population (IR) were calculated using the Australian Bureau of Statistics (ABS) estimated mid-year NSW population for 2008 from the Health Outcomes Statistical Toolkit (HOIST). ${ }^{9}$ Estimates for resident populations by country of birth were sourced from 2006 ABS census data. ${ }^{10}$ Cases were categorised into countries and regions of birth using ABS standards. ${ }^{11}$ High incidence countries were defined as countries with an incidence of over 60 cases per 100000 population, according to the World Health Organization. ${ }^{12}$

Pulmonary TB was defined as TB in a patient who had disease affecting the lung (not including the pleura), either with or without involvement of other sites. A new case of 


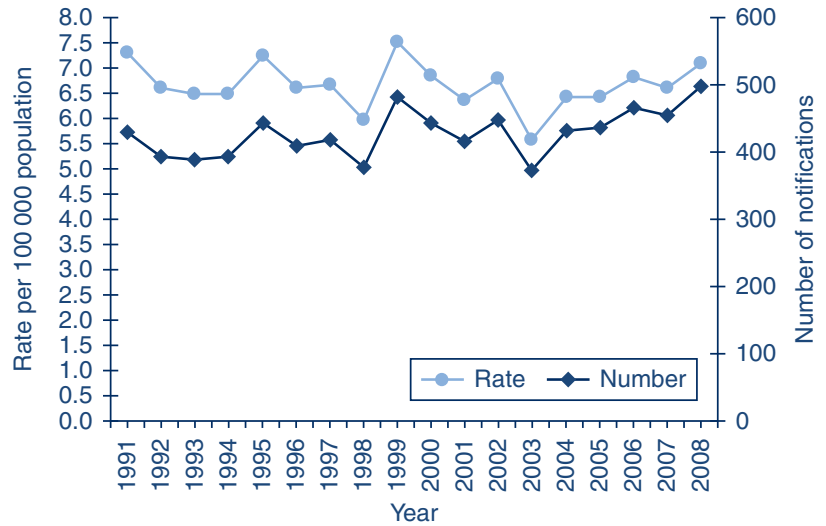

Figure 1. Annual number and rate per 100000 population of notified tuberculosis cases, NSW, 1991-2008.

Source: Notifiable Diseases Database, Communicable Diseases Branch, NSW Department of Health.

TB was a person who had not been treated for TB previously. A case of MDR-TB was defined as a person with infection with an organism that demonstrated resistance to at least isoniazid and rifampicin. ${ }^{13}$

\section{Results}

In 2008, 498 TB cases were notified in NSW and the incidence rate was 7.1 cases per 100000 population. The highest TB incidence was reported in 1999 ( $I R=7.5$, $n=481)$ and the lowest was in $2003(\mathrm{IR}=5.6, n=373)$ (Figure 1).

\section{Demographic characteristics}

In 2008, the incidence of TB was higher among people living in the Sydney metropolitan area $(\mathrm{IR}=11.1)$ than in the rest of NSW (Table 1). The area health services with the highest TB incidence were Sydney West $(\mathrm{IR}=13.3)$ and Sydney South West $(\mathrm{IR}=12.3)$.

The incidence of TB was slightly greater in males compared to females (Table 1). The age specific rates (per 100000 population) peaked in those aged $20-24$ years ( $I R=13.7), 30-34$ years $(I R=13.1)$ and over 75 years $(\mathrm{IR}=8.7)$.

Five TB cases occurred in Aboriginal men aged between 19 and 59 years (Table 1). Four resided in remote areas. Being immunocompromised $(n=2)$, having household contacts with TB $(n=3)$, and a history of homelessness $(n=1)$ were identified as risk factors for these men. One case was detected through occupational screening, and four through presentation to health care providers. There have been no notifications of TB in Aboriginal children residing in NSW since 2003.

The crude incidence of TB infection in Aboriginal Australians (3.1) and non-Aboriginal Australian-born people (1.3) in NSW is similar to or lower than the combined rate for all Australian states and territories (6.9 and 0.9 respectively in 2007).

\section{Site of infection}

In 2008, the lung was the most common principal site of disease in TB cases $(n=304,61 \%)$, followed by lymphatic tissue $(n=97,19 \%)$ (Table 2).

\section{Case classification}

Most TB cases in 2008 in NSW were newly diagnosed $(n=479,96 \%)$ (Table 2); of the 18 cases with previous diagnoses, four (36\%) had been fully treated overseas and six $(86 \%)$ had been fully treated in Australia.

\section{Laboratory confirmation}

Among the 376 cases $(76 \%)$ with laboratory confirmed M. tuberculosis, $96 \%(n=362)$ were confirmed by culture and $4 \%(n=14)$ by only nucleic acid amplification tests (NAT) (Table 2).

For cases with pulmonary disease, culture of $M$. tuberculosis in sputum was most commonly used to confirm TB $(n=225,74 \%)$. Forty percent $(n=122)$ of pulmonary cases were both direct sputum smear positive and culture or NAT positive.

\section{Clinical outcomes}

Of 498 cases, 358 (72\%) completed treatment and eight (2\%) were considered cured (negative cultures at completion of treatment). As shown in Table 3, the remainder died, moved overseas while on treatment or had not completed treatment at the time of analysis. Two cases had interrupted treatment; one had intolerance to the treatment (abnormal liver function) and the other defaulted from treatment after moving overseas.

\section{HIV co-infection}

In 2008, eight of the 269 (54\%) TB cases tested for HIV infection were positive for HIV (Figure 2). Between 1.4\% and $1.8 \%$ TB cases were HIV positive between 2005 and 2008. All these cases with co-infection were male and were born in Oceania $(n=3)$, South East-Asia $(n=3)$, Africa $(n=1)$ and South Asia $(n=1)$. The proportion of cases tested for HIV in 2008 was greater compared to previous years in NSW and the proportion tested in Australia in $2007(42 \%)^{3}$

\section{Drug resistance}

In NSW in 2008, MDR-TB was reported in one woman; she was aged in her twenties, born in Southern Asia and arrived in Australia within a year of her diagnosis. The infecting organism was resistant to isoniazid, pyrazinamide, rifampicin, streptomycin and clofazimine. Fifteen 
Table 1. Characteristics of notified tuberculosis cases, NSW, 2004-2008

\begin{tabular}{|c|c|c|c|c|c|c|c|c|c|c|c|c|c|c|c|}
\hline & \multicolumn{3}{|c|}{2004} & \multicolumn{3}{|c|}{2005} & \multicolumn{3}{|c|}{2006} & \multicolumn{3}{|c|}{2007} & \multicolumn{3}{|c|}{2008} \\
\hline & $n$ & $\%$ & Rate $^{a}$ & $n$ & $\%$ & Rate $^{a}$ & $n$ & $\%$ & Rate $^{a}$ & $n$ & $\%$ & Rate $^{a}$ & $n$ & $\%$ & Rate $^{a}$ \\
\hline \multicolumn{16}{|l|}{ Place of residence ${ }^{b}$} \\
\hline Sydney Metropolitan & 371 & 86 & 10.1 & 373 & 85 & 10.1 & 415 & 89 & 11.2 & 397 & 87 & 10.6 & 425 & 85 & 11.1 \\
\hline Outer Sydney & 40 & 9 & 2.6 & 36 & 8 & 2.3 & 32 & 7 & 2 & 35 & 8 & 2.2 & 44 & 9 & 2.8 \\
\hline Other NSW & 15 & 3 & 1 & 21 & 5 & 1.4 & 16 & 3 & 1 & 19 & 4 & 1.2 & 25 & 5 & 1.6 \\
\hline Overseas/Unknown & 6 & 1 & & 7 & 2 & & 2 & 0 & & 3 & 1 & & 4 & 1 & \\
\hline \multicolumn{16}{|l|}{ Sex } \\
\hline Male & 219 & 51 & 6.5 & 218 & 50 & 6.4 & 248 & 53 & 7.3 & 246 & 54 & 7.2 & 281 & 56 & 8.1 \\
\hline Female & 212 & 49 & 6.2 & 219 & 50 & 6.4 & 217 & 47 & 6.3 & 208 & 46 & 6 & 217 & 44 & 6.2 \\
\hline Transgender & 1 & 0 & & 0 & 0 & & 0 & 0 & & 0 & 0 & & 0 & 0 & \\
\hline \multicolumn{16}{|l|}{ Age group (years) } \\
\hline $0-4$ & 6 & 1 & 1.4 & 12 & 3 & 2.8 & 7 & 2 & 1.6 & 7 & 2 & 1.6 & 2 & 0 & 0.4 \\
\hline $5-9$ & 0 & 0 & 0 & 3 & 1 & 0.7 & 1 & 0 & 0.2 & 6 & 1 & 1.4 & 5 & 1 & 1.2 \\
\hline $10-14$ & 1 & 0 & 0.2 & 2 & 0 & 0.4 & 9 & 2 & 2 & 8 & 2 & 1.8 & 11 & 2 & 2.4 \\
\hline $15-19$ & 16 & 3 & 3.3 & 10 & 2 & 2.2 & 11 & 2 & 2.4 & 20 & 4 & 4.4 & 31 & 6 & 6.6 \\
\hline $20-24$ & 50 & 12 & 10.9 & 47 & 11 & 10.3 & 51 & 11 & 10.8 & 46 & 10 & 9.7 & 66 & 13 & 13.7 \\
\hline $25-34$ & 100 & 23 & 10.3 & 113 & 26 & 11.7 & 99 & 21 & 10.3 & 126 & 28 & 13 & 127 & 26 & 13.1 \\
\hline $35-44$ & 83 & 19 & 8.1 & 62 & 14 & 6.1 & 71 & 15 & 7.1 & 54 & 12 & 5.4 & 72 & 14 & 7 \\
\hline $45-54$ & 46 & 11 & 5.2 & 62 & 14 & 6.7 & 63 & 14 & 6.7 & 68 & 15 & 7.2 & 53 & 11 & 5.5 \\
\hline $55-64$ & 30 & 7 & 4.3 & 41 & 9 & 5.6 & 54 & 12 & 7.2 & 41 & 9 & 5.4 & 56 & 11 & 7.1 \\
\hline $65-74$ & 50 & 12 & 10.6 & 34 & 8 & 7.1 & 35 & 8 & 7.3 & 34 & 7 & 7 & 35 & 7 & 7 \\
\hline $75+$ & 50 & 12 & 6.6 & 51 & 12 & 6.6 & 64 & 14 & 14.5 & 44 & 10 & 9.7 & 40 & 8 & 8.7 \\
\hline $\begin{array}{l}\text { Aboriginal or Torres Strait } \\
\text { Islander }\end{array}$ & 3 & 1 & 2.1 & 2 & 0 & 1.4 & 4 & 1 & 2 & 3 & 1 & 2 & 5 & 100 & 3.1 \\
\hline Total & 432 & 100 & 6.4 & 437 & 100 & 6.4 & 465 & 100 & 6.8 & 454 & 100 & 6.6 & 498 & 100 & 7.1 \\
\hline \multicolumn{16}{|c|}{$\begin{array}{l}\text { a Rates per } 100000 \text { population are calculated by the corresponding year's population mid-year estimates. } \\
\text { 'Desidence by area health service (AHS) as follows: Sydney Metropolitan = Sydney South West AHS, the Northern Sydney region of Northern Sydney/ } \\
\text { Central Coast AHS, the South East Sydney region of South East Sydney and Illawarra AHS and the Eastern region of Sydney West AHS. Outer } \\
\text { Sydney = Western region of Sydney West AHS, the Central Coast region of Northern Sydney/Central Coast AHS, Illawarra region of South East Sydney } \\
\text { and Illawarra AHS and the Hunter region of Hunter and New England AHS. Other NSW = New England region of Hunter and New England AHS, North } \\
\text { Coast AHS, Greater Southern AHS, Greater Western AHS and Justice Health. } \\
\text { NB: In } 2004 \text { there was one transgender case included in the total but not the sex breakdown. } \\
\text { Source: Notifiable Diseases Database, Communicable Diseases Branch, NSW Department of Health. }\end{array}$} \\
\hline
\end{tabular}

MDR-TB cases were identified in NSW between 2003 and 2007 , an average of 3.8 cases annually.

In 2008, $20(4 \%) \mathrm{TB}$ cases had organisms that were resistant to isoniazid only. These people were born in South East Asia $(n=6)$, North East Asia $(n=5)$, Australia $(n=3)$, South and Central Asia $(n=2)$, Europe $(n=2)$, Africa $(n=1)$ and the Americas $(n=1)$. Monoresistance to rifampicin was found in one case, and to pyrazinamide in two cases. Three cases had infection with organisms resistant to two of four first-line drugs (not isoniazid and rifampicin).

\section{Risk factors}

The most commonly reported risk factor for TB among cases reported in NSW in 2008 was past residence in a high incidence country $(n=429,86 \%)$. Most common risk factors were: being born in a high incidence country $(n=386,78 \%)$; having household or close contacts with TB $(n=85,17 \%)$; and being immunosuppressed $(n=73$, $15 \%)$ (Table 4).

There was no evidence of transmission of TB within a health-care setting in NSW in 2008. Consistent with previous years, some TB cases had worked in the health care industry at some time and had resided previously in high incidence countries (Table 5).

\section{Risk factors for Australian-born cases}

Sixty-one notified cases (12\%) were born in Australia. The median age of onset of TB in these cases was 52 years (range 0-93 years) and 41 (67\%) were men. The most 
Table 2. Main site of infection, case classification and means of laboratory confirmation of notified tuberculosis cases, NSW, 2004-2008

\begin{tabular}{|c|c|c|c|c|c|c|c|c|c|c|}
\hline \multirow[t]{2}{*}{ Case characteristics } & \multicolumn{2}{|c|}{2004} & \multicolumn{2}{|c|}{2005} & \multicolumn{2}{|c|}{2006} & \multicolumn{2}{|c|}{2007} & \multicolumn{2}{|c|}{2008} \\
\hline & $n$ & $\%$ & $n$ & $\%$ & $n$ & $\%$ & $n$ & $\%$ & $n$ & $\%$ \\
\hline \multicolumn{11}{|l|}{ Main site } \\
\hline Lung & 262 & 61 & 252 & 58 & 278 & 60 & 221 & 49 & 242 & 49 \\
\hline Lung plus other site & $\mathrm{n} / \mathrm{a}$ & $n / a$ & $\mathrm{n} / \mathrm{a}$ & $n / a$ & $\mathrm{n} / \mathrm{a}$ & $n / a$ & 47 & 10 & 62 & 12 \\
\hline Lymphatics only & 92 & 21 & 97 & 22 & 88 & 19 & 79 & 17 & 97 & 19 \\
\hline Pleura only & 19 & 4 & 21 & 5 & 28 & 6 & 37 & 8 & 28 & 6 \\
\hline Bone/Joint only & 15 & 3 & 16 & 4 & 21 & 5 & 20 & 4 & 11 & 2 \\
\hline Kidney-genito-urinary only & 14 & 3 & 13 & 3 & 10 & 2 & 13 & 3 & 10 & 2 \\
\hline Miliary only & 2 & 0 & 0 & 0 & 1 & 0 & 0 & 0 & 0 & 0 \\
\hline Brain/CNS only & 8 & 2 & 11 & 3 & 10 & 2 & 6 & 1 & 10 & 2 \\
\hline Gastrointestinal only & 7 & 2 & 6 & 1 & 11 & 2 & 14 & 3 & 12 & 2 \\
\hline Other only & 13 & 3 & 19 & 4 & 18 & 4 & 19 & 4 & 24 & 5 \\
\hline Unknown/Not reported & 0 & 0 & 2 & 0 & 0 & 0 & 0 & 0 & 2 & 0 \\
\hline \multicolumn{11}{|l|}{ Case classification } \\
\hline New active & 413 & 96 & 423 & 97 & 438 & 94 & 436 & 96 & 479 & 96 \\
\hline Cases with a previous diagnosis & 19 & 4 & 12 & 3 & 27 & 6 & 17 & 4 & 18 & 4 \\
\hline Following treatment in Australia & 7 & 2 & 7 & 2 & 2 & 0 & 4 & 1 & 7 & 1 \\
\hline Following treatment overseas & 12 & 3 & 5 & 1 & 25 & 5 & 13 & 3 & 11 & 2 \\
\hline Unknown/Not reported & 0 & 0 & 2 & 0 & 0 & 0 & 1 & 0 & 1 & 0 \\
\hline Laboratory confirmed (total) & 312 & 72 & 333 & 76 & 347 & 75 & 334 & 74 & 376 & 76 \\
\hline Culture & 296 & 69 & 310 & 71 & 320 & 69 & 320 & 71 & 362 & 96 \\
\hline PCR only ${ }^{a}$ & 16 & 4 & 23 & 5 & 27 & 6 & 14 & 3 & 14 & 4 \\
\hline Clinical only & 120 & 28 & 104 & 24 & 118 & 25 & 120 & 26 & 122 & 24 \\
\hline Pulmonary cases only & 262 & 61 & 252 & 58 & 278 & 60 & 266 & 59 & 304 & 61 \\
\hline \multicolumn{11}{|l|}{ Direct smear results ${ }^{c}$} \\
\hline Direct smear positive & 110 & 42 & 116 & 46 & 111 & 40 & 112 & 42 & 127 & 42 \\
\hline Direct smear negative & 142 & 54 & 116 & 46 & 153 & 55 & 135 & 51 & 192 & 63 \\
\hline Not reported & 10 & 4 & 20 & 8 & 14 & 5 & 19 & 7 & 14 & 5 \\
\hline \multicolumn{11}{|l|}{ Pulmonary cases only } \\
\hline \multicolumn{11}{|l|}{ Culture results ${ }^{c}$} \\
\hline Culture positive & 204 & 78 & 190 & 75 & 221 & 79 & 201 & 76 & 225 & 74 \\
\hline Culture negative & 49 & 19 & 42 & 17 & 43 & 15 & 43 & 16 & 65 & 21 \\
\hline Not reported & 9 & 3 & 20 & 8 & 14 & 5 & 22 & 8 & 14 & 5 \\
\hline Total number of cases & 432 & 100 & 437 & 100 & 465 & 100 & 454 & 100 & 498 & 100 \\
\hline
\end{tabular}

common risk factors for Australian-born TB cases were: having a household member with TB $(n=18,29.5 \%)$; immunosuppression $(n=16,26.2 \%)$; and previous residence in a high incidence country $(n=14,23.0 \%)$ (Table 6). Twenty-five (41\%) Australian-born TB cases had multiple risk factors.

Australian-born cases with no identified risk factors $(n=10,16 \%)$ were similar to all Australian-born cases; their median age at onset was 52 and $70 \%$ were men.

\section{Risk factors for overseas-born cases}

Most TB cases were born overseas $(n=437,88 \%)$. Apart from being born overseas, the most common risk factors for these cases were having a household contact with TB $(n=67,15.3 \%)$ and an immunosuppressive health status $(n=57,13.0 \%)$.

Eighty-eight percent (386) of cases born overseas were born in a high TB incidence country. The median age of onset of cases born in high incidence countries was 32 years 
(range $7-90$ years); 56\% $(n=216)$ were men. The median length of stay in Australia prior to disease onset was 4 years (range $0-50$ years). The remaining $12 \%$ of cases $(n=51)$ were born in Australia or overseas in countries other than those with a high incidence of TB, most commonly New

Table 3. Clinical outcome of tuberculosis cases, NSW, 2007-2008

\begin{tabular}{|c|c|c|c|c|}
\hline \multirow[t]{2}{*}{ Outcome } & \multicolumn{2}{|c|}{2007} & \multicolumn{2}{|c|}{$2008^{a}$} \\
\hline & $n$ & $\%$ & $n$ & $\%$ \\
\hline Treatment success & 392 & 86 & 366 & 74 \\
\hline Completed & 378 & 83 & 358 & 72 \\
\hline Cured $^{\mathrm{b}}$ & 14 & 3 & 8 & 2 \\
\hline Defaulted & 11 & 2 & 10 & 2 \\
\hline Died of TB & 1 & 0 & 2 & 0 \\
\hline Failure ${ }^{c}$ & 0 & 0 & 0 & 0 \\
\hline Treatment interrupted $^{d}$ & 0 & 0 & 2 & 0 \\
\hline Unknown outcome & 0 & 0 & 0 & 0 \\
\hline $\begin{array}{l}\text { Died of other cause during } \\
\text { treatment }\end{array}$ & 20 & 4 & 20 & 4 \\
\hline Transferred overseas & 22 & 5 & 24 & 5 \\
\hline $\begin{array}{l}\text { Incomplete - still undergoing } \\
\text { treatment }\end{array}$ & 7 & 2 & 74 & 15 \\
\hline Total number of cases & 454 & 100 & 498 & 100 \\
\hline $\begin{array}{l}\text { a Outcome of } 2008 \text { cases is prelimin } \\
\text { mid-2010. } \\
\text { b Bacteriologically confirmed cure o } \\
\text { pulmonary cases. } \\
\text { 'Treatment completed but case no } \\
\text { 'T Treatment interrupted for two mo } \\
\text { Source: Notifiable Diseases Databa } \\
\text { Branch, NSW Department of Health }\end{array}$ & $\begin{array}{l}\text { ry data } \\
\text { smear } \\
\text { cured. } \\
\text { ths or } r \\
\text {, Comn }\end{array}$ & $\begin{array}{l}\text { to be } \\
\text { cultur }\end{array}$ & $\begin{array}{l}\text { onfirme } \\
\text { positiv }\end{array}$ & \\
\hline
\end{tabular}

Zealand $(n=6)$ and Fiji $(n=6)$. The median age of onset for these cases was 51 years (range $1-88$ years) and $49 \%$ $(n=24)$ were men. The median length of stay in Australia prior to onset was 17 years (range $0-62$ years).

\section{Country of birth}

The incidence of TB among people born in Southern and Central Asia increased from 68.1 to 146.0 cases per 100000 population over the 5 -year period to 2008 in NSW. Incidence rates among people born in other areas of Asia have remained steady (Figure 3). By sub-region, incidence was highest in people born in Central and Western Africa (IR=200.4), Central Asia (IR=147.5) and Southern Asia (IR=145.9). TB notification rates in other areas were relatively stable between 2004 and 2008 (Figure 4).

Compared to TB cases reported in 2007 (who arrived between 2003 and 2007), there was an increase of 37 cases who were born in Afghanistan, Nepal, Vietnam and India in 2008 (who arrived between 2004 and 2008) (Table 7). Between 2005 and 2008, the number of visas granted and permanent arrivals to Australia from Afghanistan and Nepal (in Southern Asia) more than doubled but was relatively stable from Vietnam (in South East Asia) (Chief Medical Officer, Department of Immigration and Citizenship, pers. comm.).

\section{Contact tracing}

Contact tracing resulting from the follow up of the 498 cases of TB in NSW in 2008 identified 2712 people at risk of TB infection. Of those who underwent appropriate further investigations (including a tuberculin skin test), $18(0.8 \%)$ had active TB infections. Six percent $(n=125)$

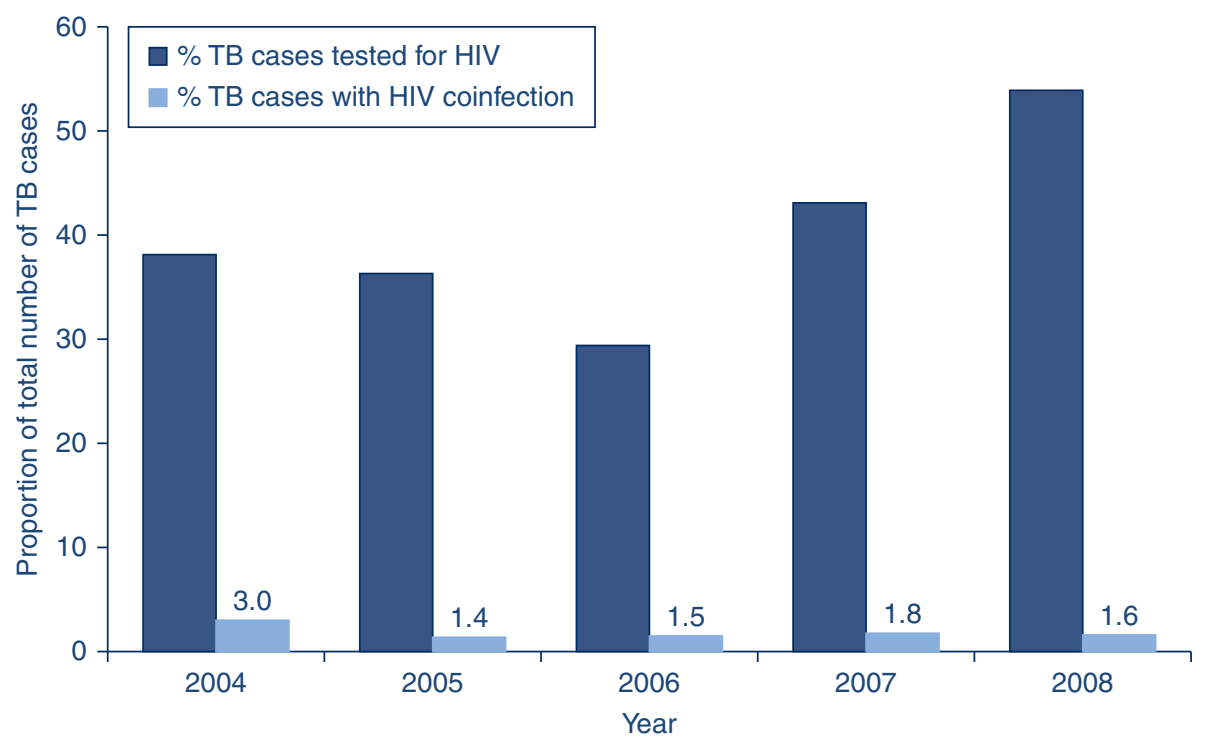

Figure 2. Proportion of tuberculosis cases tested for HIV and proportion of all notified tuberculosis cases with HIV infection, NSW, 2004-2008.

Source: Notifiable Diseases Database, Communicable Diseases Branch, NSW Department of Health. 
of assessed contacts were prescribed preventive therapy (Table 8).

\section{Discussion}

Most TB disease in NSW occurred in people who were born in countries with a high incidence of TB. The highest incidence in NSW was among people living in the Sydney metropolitan area, reflecting settlement patterns of migrants as most initially settle in metropolitan areas. ${ }^{14}$ The median age of onset of TB among people born in high incidence countries was 20 years lower than for Australian-born cases. Disease in people born overseas tends to be acquired in high incidence countries prior to arrival in Australia and transmission to Australian-born people remains minimal. ${ }^{15,16}$

Although the incidence of TB in NSW increased slightly in 2008, it has remained steady over the last decade despite sustained migration from high incidence countries. ${ }^{2}$ High treatment success, absence of treatment failures and low rates of relapse of cases initially treated in Australia demonstrate strong control aspects of the TB program.

The increased rate of TB in 2008 in NSW is likely due to an increased number of cases among newly arrived people from Afghanistan, Nepal, Vietnam and India, possibly related to changing migration patterns. While the precise

Table 4. Reported risk factors for notified tuberculosis cases, NSW, 2007-2008

\begin{tabular}{|c|c|c|c|c|}
\hline \multirow[t]{2}{*}{ Risk factor } & \multicolumn{2}{|c|}{2007} & \multicolumn{2}{|c|}{2008} \\
\hline & $n$ & $\%$ & $n$ & $\%$ \\
\hline Past residence in a high incidence country & 400 & 88 & 429 & 86 \\
\hline Born in a high incidence country & 336 & 74 & 386 & 78 \\
\hline Immunosuppressive health status/Therapy & 63 & 14 & 73 & 15 \\
\hline Household member or close contact with TB & 65 & 14 & 85 & 17 \\
\hline Previous TB diagnosis & 25 & 6 & 28 & 6 \\
\hline Ever worked in health industry & 32 & 7 & 42 & 8 \\
\hline Currently or recently residing in a residential institution & 14 & 3 & 15 & 3 \\
\hline Child's parent/s born in high incidence country ${ }^{a}$ & 10 & 2 & 21 & 4 \\
\hline Currently or recently residing in a homeless shelter & 5 & 1 & 11 & 2 \\
\hline Currently or previously employed in a residential institution & 15 & 3 & 11 & 2 \\
\hline Other & 0 & 0 & 34 & 7 \\
\hline Nil (2008 only) & & & 21 & 4 \\
\hline Number of cases & 454 & & 498 & \\
\hline
\end{tabular}

Table 5. Notified tuberculosis cases in health care workers, NSW, 2004-2008

\begin{tabular}{|c|c|c|c|c|c|c|c|c|c|c|}
\hline \multirow[t]{2}{*}{ Risk factor } & \multicolumn{2}{|c|}{2004} & \multicolumn{2}{|c|}{2005} & \multicolumn{2}{|c|}{2006} & \multicolumn{2}{|c|}{2007} & \multicolumn{2}{|c|}{2008} \\
\hline & $n$ & $\%$ & $n$ & $\%$ & $n$ & $\%$ & $n$ & $\%$ & $n$ & $\%$ \\
\hline Ever worked in HCF - total & 21 & 5 & 40 & 9 & 31 & 7 & 32 & 7 & $42^{\mathrm{a}}$ & 8 \\
\hline Ever worked in HCF - born overseas & 18 & 4 & 32 & 7 & 27 & 6 & 27 & 6 & 37 & 7 \\
\hline Length of stay in Australia $<3$ years & 10 & 2 & 10 & 2 & 12 & 3 & 10 & 2 & 16 & 3 \\
\hline Length of stay in Australia $\geq 3$ years & 8 & 2 & 20 & 5 & 15 & 3 & 17 & 4 & 21 & 4 \\
\hline Currently working/worked in last 12 months in HCF & 14 & 3 & 25 & 6 & 19 & 4 & 26 & 6 & 18 & 4 \\
\hline \multicolumn{11}{|l|}{ By occupation } \\
\hline Medical/Nursing & 13 & 3 & 21 & 5 & 17 & 4 & 18 & 4 & 16 & 3 \\
\hline Allied Health including Dental & 1 & 0 & 1 & 0 & 1 & 0 & 3 & 1 & 0 & 0 \\
\hline Other ${ }^{b}$ & 1 & 0 & 3 & 1 & 1 & 0 & 5 & 1 & 2 & 0 \\
\hline Total number of cases & 432 & 100 & 437 & 100 & 465 & 100 & 454 & 100 & 498 & 100 \\
\hline
\end{tabular}


Table 6. Distribution of risk factors reported by notified tuberculosis cases, by country of birth, NSW, 2008

\begin{tabular}{|c|c|c|c|c|c|}
\hline \multirow[t]{2}{*}{ Risk factor } & \multicolumn{2}{|c|}{ Australian-born cases } & \multicolumn{2}{|c|}{ Overseas-born cases } & \multirow{2}{*}{$\begin{array}{c}\text { Total } \\
n\end{array}$} \\
\hline & $n$ & $\%$ & $n$ & $\%$ & \\
\hline Household member or close contact with TB & 18 & 29.5 & 67 & 15.3 & 85 \\
\hline Past residence in a high incidence country ${ }^{\mathrm{a}}$ & 14 & 23 & 415 & 95 & 429 \\
\hline Immunosuppressive health status/therapy & 16 & 26.2 & 57 & 13 & 73 \\
\hline Currently or ever residing in a homeless shelter & 2 & 3.3 & 9 & 2.1 & 11 \\
\hline Currently or previously employed in a residential institution & 2 & 3.3 & 9 & 2.1 & 11 \\
\hline Currently or recently residing in a residential institution & 3 & 4.9 & 12 & 2.7 & 15 \\
\hline Ever worked in health industry & 5 & 8.2 & 37 & 8.5 & 42 \\
\hline Child's parent/s born in high incidence country ${ }^{\mathrm{b}}$ & 5 & 8.2 & $\mathrm{n} / \mathrm{a}$ & $n / a$ & $\mathrm{n} / \mathrm{a}$ \\
\hline Previous TB diagnosis & 4 & 6.6 & 24 & 5.5 & 28 \\
\hline Other risk factor & 5 & 8.2 & 29 & 6.6 & 34 \\
\hline Born in a high incidence country ${ }^{c}$ & $\mathrm{n} / \mathrm{a}$ & $n / a$ & 386 & 88.3 & 383 \\
\hline No risk factors identified & 10 & 16.4 & 11 & 2.5 & 21 \\
\hline \multicolumn{6}{|l|}{ Identification method } \\
\hline Clinical presentation & 49 & 80.3 & 368 & 84.2 & 417 \\
\hline Contact tracing & 7 & 11.5 & 16 & 3.7 & 23 \\
\hline Screening & 1 & 1.6 & 46 & 10.5 & 47 \\
\hline Other/Unknown & 4 & 6.6 & 7 & 1.6 & 11 \\
\hline Total & 61 & 100 & 437 & 100 & 498 \\
\hline \multicolumn{6}{|c|}{$\begin{array}{l}\text { a Country of residence is a yes/no field so specific countries are not documented. It is possible there is some misclassification of the country } \\
\text { of residence as high incidence. } \\
\text { b Refers to children under the age of } 15 \text { who were born in Australia but whose parents were born in a high incidence country. } \\
\text { cThe specific country of birth was documented and classification was based on this data. } \\
\text { Source: Notifiable Diseases Database, Communicable Diseases Branch, NSW Department of Health. }\end{array}$} \\
\hline
\end{tabular}

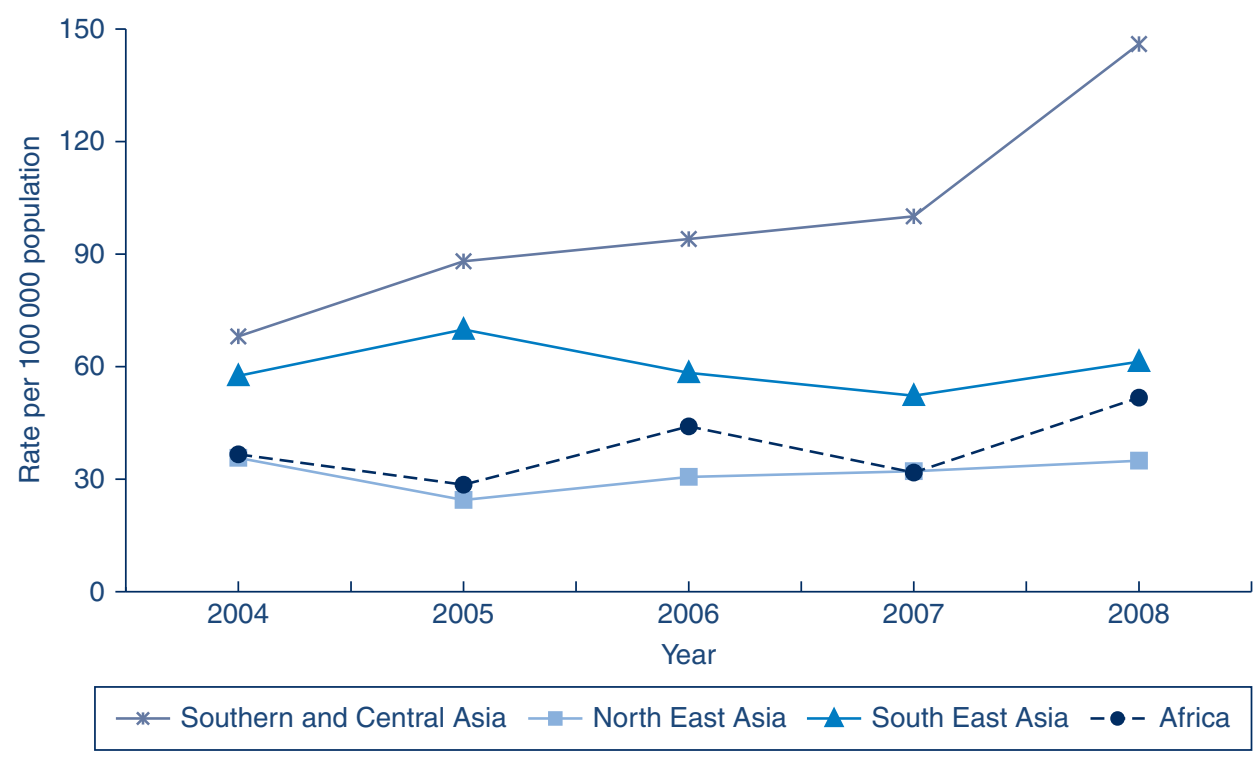

Figure 3. Rate per 100000 population of notified tuberculosis cases by region of birth, NSW, 2004-2008.

Source: Notifiable Diseases Database, Communicable Diseases Branch, NSW Department of Health.

number of newly arrived migrants to NSW and of temporary visas granted is unknown, nationally, the number of visas granted and permanent arrivals from these countries increased substantially in 2008 .
The National Tuberculosis Advisory Committee has recommended that all TB cases should be routinely offered HIV testing ${ }^{3}$ as risk factor assessment does not reliably predict HIV infection in TB patients. ${ }^{17}$ The 


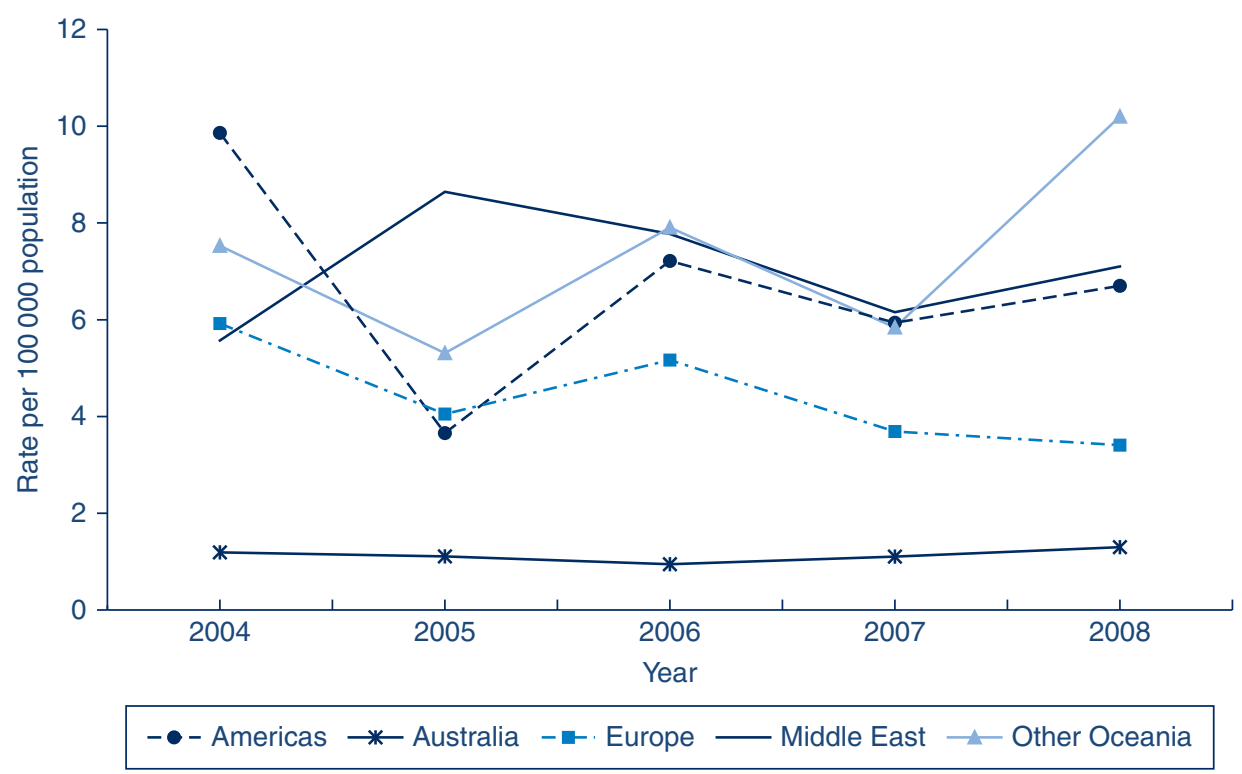

Figure 4. Rate per 100000 population of notified tuberculosis cases by region of birth, NSW, 2004-2008.

Source: Notifiable Diseases Database, Communicable Diseases Branch, NSW Department of Health.

Table 7. Number of notified tuberculosis cases born in selected countries, NSW, 2007-2008

\begin{tabular}{|c|c|c|c|c|}
\hline \multirow[t]{2}{*}{ Country of birth } & \multirow{2}{*}{$2007^{\mathrm{a}}$} & \multirow{2}{*}{$2008^{\mathrm{b}}$} & \multicolumn{2}{|c|}{$\begin{array}{l}\text { Increase in } 2008^{b} \\
\text { from } 2007^{a}\end{array}$} \\
\hline & & & $n$ & $\%$ \\
\hline Afghanistan & 2 & 10 & 8 & 3.6 \\
\hline Nepal & 11 & 22 & 11 & 4.4 \\
\hline Vietnam & 6 & 14 & 8 & 3.3 \\
\hline India & 49 & 59 & 10 & 1.7 \\
\hline \multicolumn{5}{|c|}{$\begin{array}{l}\text { a Cases with a report year in } 2007 \text { who arrived in Australia between } \\
2003 \text { and } 2007 \text {. } \\
\text { b Cases with a report year in } 2008 \text { who arrived in Australia between } \\
2004 \text { and } 2008 \text {. }\end{array}$} \\
\hline
\end{tabular}

proportion of TB cases in NSW tested for HIV infection has increased annually to just over $50 \%$ in 2008 . Knowing the HIV status of TB cases in NSW may become increasingly important as the risk of HIV has the potential to increase in some injecting drug-using populations ${ }^{18}$ and the Papua New Guinea-Torres Strait Islands crossborder region. 8,19

A threat to tuberculosis control in Australia is the increasing incidence of MDR-TB in surrounding countries and regions. Treatment for MDR-TB is more complex and lengthy, and is often associated with poorer outcomes than for drug-sensitive TB. It is estimated that approximately $2 \%$ of TB cases in India and Vietnam have MDR-TB, ${ }^{7}$ and up to $7 \%$ of new cases in China have MDR-TB. ${ }^{20}$ Considering the number of migrants from these countries to
Table 8. Outcomes of contact tracing of notified tuberculosis cases, NSW, 2007-2008

\begin{tabular}{|c|c|c|c|c|}
\hline \multirow[t]{2}{*}{ Contact tracing outcomes } & \multicolumn{2}{|c|}{2007} & \multicolumn{2}{|c|}{2008} \\
\hline & $n$ & $\%$ & $n$ & $\%^{a}$ \\
\hline Contacts identified & 2725 & - & 2712 & - \\
\hline Contacts screened & 2345 & $86^{\mathrm{a}}$ & 2195 & $81^{\mathrm{a}}$ \\
\hline Contacts with active TB & 28 & $7^{\mathrm{b}}$ & 18 & $1^{\mathrm{b}}$ \\
\hline $\begin{array}{l}\text { Contacts TST + ve on initial } \\
\text { screen }\end{array}$ & 783 & $33^{\mathrm{b}}$ & 779 & $35^{\mathrm{b}}$ \\
\hline $\begin{array}{l}\text { Contacts TST + ve with risk } \\
\text { factors for exposure/BCG }\end{array}$ & 673 & $29^{\mathrm{b}}$ & 658 & $30^{\mathrm{b}}$ \\
\hline Contacts with TST conversion & 80 & $3^{\mathrm{b}}$ & 66 & $3^{b}$ \\
\hline Contacts on preventive therapy & 136 & $6^{\mathrm{b}}$ & 125 & $6^{\mathrm{b}}$ \\
\hline \multicolumn{5}{|c|}{$\begin{array}{l}\text { aPercentage of all contacts identified. } \\
\text { bPercentage of all contacts screened. } \\
\text { Source: Notifiable Diseases Database, Communicable Diseases } \\
\text { Branch, NSW Department of Health. }\end{array}$} \\
\hline
\end{tabular}

Australia, the risk of increased numbers of MDR-TB cases is significant.

\section{Conclusion}

This report demonstrates that the incidence of TB in NSW has remained stable over recent years. TB remains a disease that mostly affects people born in countries with a high incidence of TB and there is little evidence of local transmission. Central to the success of the NSW TB program is the continued effective collaboration with stakeholders in NSW, other Australian states and 
territories and neighbouring countries in the management of TB.

\section{Acknowledgments}

We acknowledge the role of staff of the chest clinics, public health units, laboratories, doctors in collecting and reporting data on TB cases in NSW. In particular we acknowledge Vitali Sintchenko and Peter Jelfs from the Institute of Clinical Pathology and Medical Research.

\section{References}

1. Pratt R, Grange J, Williams V. Tuberculosis A foundation for nursing and healthcare practice. London: Hodder Education; 2005.

2. World Health Organization. Global tuberculosis control - a short update to the 2009 report. Geneva: World Health Organization WHO/HTM/TB/2009.42, 2009. Available from: http://www. who.int/tb/publications/global_report/2009/update/en/index. htm (Cited 10 January 2010.)

3. Barry C, Konstantinos A, National Tuberculosis Advisory Committee. Tuberculosis notifications in Australia, 2007. Commun Dis Intell 2009; 33(3): 304-15.

4. O'Connor BA, Fritsche LL, Christensen AJ, McAnulty JM. EpiReview: Tuberculosis in NSW, 2003-2007. N S W Public Health Bull 2009; 20(3-4): 59-68.

5. Heymann DL, editor. Control of Communicable Diseases Manual. 19th ed. Washington: American Public Health Association; 2008.

6. WHO/IUATLD global project on anti-tuberculosis drug resistance surveillance. Anti-tuberculosis drug resistance in the world: third global report 1999-2002. Geneva: World Health Organization; 2004. Report No. WHO/HTM/TB/ 2004.343.

7. WHO/IUATLD Global Project on Anti-tuberculosis Drug Resistance Surveillance. Anti-tuberculosis drug resistance in the world: fourth global report 2002-2007. Geneva: World Health Organization; 2008. Report No. WHO/HTM/TB/ 2008.394.

8. Lumb R, Bastian I, Carter R, Jelfs P, Keehner T, Sievers A. Tuberculosis in Australia: bacteriologically confirmed cases and drug resistance, 2007. Commun Dis Intell 2009; 33(3): 298-303.
9. Centre for Epidemiology and Research, NSW Health. Population Datasets Documentation Version 2.3. Available from: http://hoist.health.nsw.gov.au/hoist/dataset/pops/pops. htm (Cited 8 August 2009.)

10. Australian Bureau of Statistics. Migration, Australia, 2006-07 (Category.3412.0). Canberra: Commonwealth of Australia; 2008.

11. Australian Bureau of Statistics. Standard Australian Classification of Countries (SACC), Second Edition (Category 1269.0). Canberra: Commonwealth of Australia; 2008.

12. World Health Organization. Global health atlas. Available from: http://apps.who.int/globalatlas/default.asp (Cited 23 December 2009.)

13. National Tuberculosis Advisory Committee. Multi-drug resistant tuberculosis Information Paper (October 2007). Commun Dis Intell 2007; 31(4): 406-9.

14. Burnley I. The impact of immigration in Australia: a demographic approach. Melbourne: Oxford University Press; 2001.

15. Watkins RE, Plant AJ. Predicting tuberculosis among migrant groups. Epidemiol Infect 2002; 129(3): 623-8. doi:10.1017/ S0950268802007604

16. Dasgupta K, Menzies D. Cost-effectiveness of tuberculosis control strategies among immigrants and refugees. Eur Respir $J$ 2005; 25: 1107-16. doi:10.1183/09031936.05.00074004

17. Emerson CR, Post JJ. To routinely offer testing for HIV infection in all cases of tuberculosis: a rational clinical approach? Med $J$ Aust 2008; 188(3): 162-3.

18. 6th National HIV Strategy, Draft. September 2009. Available from: http://www.ashm.org.au/default2.asp?active_page_ $\mathrm{id}=350$ (Cited 23 December 2009.)

19. Sladden T. Twenty years of HIV surveillance in the Pacificwhat do the data tell us and what do we still need to know? Pac Health Dialog 2005; 12(2): 23-37.

20. He GX, Zhao YL, Jiang GL, Liu YH, Xia H, Wang SF et al. Prevalence of tuberculosis drug resistance in 10 provinces of China. BMC Infect Dis 2008; 8: 166. doi:10.1186/ 1471-2334-8-166 